\title{
An Integrated Analysis of Migration and Remittances: Modeling Migration as a Mechanism for Selection
}

\section{Citation}

Garip, Filiz. 2012. An integrated analysis of migration and remittances: modeling migration as a mechanism for selection. Population Research and Policy Review 31(5): 637-663.

\section{Published Version}

doi:10.1007/s11113-012-9246-5

\section{Permanent link}

http://nrs.harvard.edu/urn-3:HUL.InstRepos:10872800

\section{Terms of Use}

This article was downloaded from Harvard University's DASH repository, and is made available under the terms and conditions applicable to Open Access Policy Articles, as set forth at http:// nrs.harvard.edu/urn-3:HUL.InstRepos:dash.current.terms-of-use\#OAP

\section{Share Your Story}

The Harvard community has made this article openly available. Please share how this access benefits you. Submit a story.

Accessibility 


\title{
An Integrated Analysis of Migration and Remittances: Modeling Migration as a Mechanism for Selection
}

[Published in Population Research \& Policy Review 31(5), pp. 393-433, 2012]

\author{
Filiz Garip \\ Department of Sociology \\ Harvard University
}




\begin{abstract}
Prior work has modeled individuals' migration and remittance behavior separately, and reported mixed empirical support for various remittance motivations. This study offers an integrated approach, and considers migration as a mechanism for selection in a censored probit model of remittance behavior. This approach leads to different conclusions about the determinants of remittance behavior in the Thai internal migration setting. To the extent that these determinants capture different remittance motivations, as prior research has presumed, the analysis also provides varying support for these motivations. These results suggest that migration and remittance behavior are interrelated, and it is crucial for an analysis of remittance behavior to control for the selectivity of migration.
\end{abstract}

Keywords: Migration, Remittances, Selectivity, Thailand. 


\section{Introduction}

International remittances, funds and goods sent by migrants to origin countries, have reached 240 billion US\$ annually, becoming the second largest source of external finance for the developing world after foreign direct investment (Ratha and $\mathrm{Xu}$ 2008). Remittances from internal migrants, although smaller in magnitude, also comprise a vital component of rural livelihoods in many developing countries (Reardon 1997; Rempel and Lobdell 1978). Research shows that remittances relax budget or credit constraints in origin households (Lauby and Stark 1988; Lucas and Stark 1985; Stark and Levhari 1982; Taylor 1999) and provide opportunities for income redistribution and poverty reduction in origin communities or countries (Durand et al. 1996a; Durand, Parrado and Massey 1996b; Jones 1998; Rapoport and Docquier 2006; Russell 1986; Taylor et al. 1996). To anticipate the macro-level consequences of these flows, we first need to understand the micro-level motives shaping individuals' remittance behavior.

Prior research has provided various motives to explain why migrants remit. The altruistic motive suggests that migrants remit to improve their households' welfare (Agarwal and Horowitz 2002; Banerjee 1984; Johnson and Whitelaw 1974; Lillard and Willis 1997). The exchange motive implies that migrants remit to buy services or to secure future inheritances from households (Cox 1987; Cox, Eser and Jimenez 1998; de la Briere et al. 2002; Hoddinott 1994; Sana 2005). The insurance motive attributes remittances to a mutual risk diversification arrangement between the migrant and the household (Rosenzweig 1988; Stark and Levhari 1982), while the investment motive views remittances as a repayment for past loans from the household (Ahlburg and Brown 1998; Cai 2003; Lucas and Stark 1985; Poirine 1997; Stark and Bloom 1985). 
Empirical studies to date yielded inconsistencies in attributing migrants' remittance behavior to altruistic, exchange, insurance or investment motives. These inconsistencies can be connected to two major issues. First, because different remittance motives carry similar empirical implications, it is difficult to discriminate among alternative explanations. Second, because remittances are observed for migrants, a non-random subset of the population, the determinants of remitting are often confounded with the selection process into the migrant sample. ${ }^{1}$

This study seeks to address both issues. First, drawing on recent work by Rapoport and Docquier (2006), I employ a unified theoretical framework and combine empirical predictions from various remittance motives. Following the conventional approach in the literature, I first study migrants alone, and test these empirical predictions in an isolated probit model of remittance behavior in rural Thailand. This setting provides a rich source of information from almost 12,000 individuals in 22 rural villages, about a fifth of whom have migrated to major urban destinations. Second, I compare the results from the isolated analysis to those from an integrated analysis of migration and remittance behavior. This analysis treats migration as a mechanism for selection in a censored probit model of remittance behavior and manages the selection bias that may have confounded empirical results in prior work.

Compared to an isolated analysis of remittances, the selection-corrected model leads to different conclusions about the determinants of remittance behavior in the Thai setting. To the extent that these determinants capture different remittance motivations, as presumed in prior work and

\footnotetext{
${ }^{1}$ The inconsistencies in findings can also be attributed to differences in context or data. Carling (2008) notes that differences in the migration context, family structure and societal norms may account for the variance in remittance motives across settings. Similarly, Rapoport and Docquier (2006) argue that the nature of data (e.g., cross-sectional versus longitudinal) can determine the extent of evidence for various remittance motives.
} 
summarized in Rapoport and Docquier (2006), the analysis also provides varying support for these motivations.

These findings suggest that migration and remittance behavior are connected, and any analysis of remittances should consider the selectivity of migration. The findings also demonstrate the value of the theoretical framework in Rapoport and Docquier (2006), which, combined with the selection-corrected model suggested here, may help us reconcile the mixed empirical results in the literature and accumulate coherent and comparable findings about remittance behavior from various settings.

\section{Background}

Prior research has suggested a number of competing models that relate remittance behavior to altruistic, exchange, insurance or investment motives ${ }^{2}$. Rapoport and Docquier (2006) recently reviewed this literature and outlined the assumptions and predictions of various models. Drawing on their unifying framework, below, I briefly describe each model of remittance behavior, state its main predictions, and refer to the empirical work supporting it. ${ }^{3}$ To aid the exposition, in Table 1, I summarize the predictions from the four models. ${ }^{4}$ Each column corresponds to a

\footnotetext{
${ }^{2}$ Many of the key studies on remittance motivations relied on data from internal (often urban-to-rural) remittances. Lucas and Stark (1985) tested altruistic and self-interested motives to remit with data from internal migrants in Bostwana. Hoddinott (1994) found evidence of investment and inheritance-seeking hypotheses among urban migrants in western Kenya. VanWey (2004) compared the prevalence of altruistic and contractual remittance behavior among men and women in a sample of internal migrants in Thailand. Indeed, as Carling (2008, p.581) noted in his recent review, "Research on the determinants of remittances continues to be heavily influenced by a few studies of internal migration in developing countries in the 1980s." The underlying assumption in the literature, then, is that similar behavioral models govern internal and international remittance flows.

${ }^{3}$ These predictions relate various factors to the amount of remittances. Due to limitations of the Thai data (described in note 8), in this study, I focus on whether migrants remit or not, rather than how much they remit. To model the remittance amount, one can apply the standard Heckman procedure: a probit model of migration followed by an OLS model of the remittance amount (assigning zero remittances to nonremitting migrants).

${ }^{4}$ This table is based on Docquier and Rapoport's (2006) Table 2 (p.39), but differs in three respects. First, I do not report the predictions related to the strategic motive of remittances. This motive suggests that migrants' remittances
} 
specific model and each row lists an explanatory factor (and its proxy in the Thai data, explained in detail in a subsequent section). Each cell displays the expected effect of a factor on the probability (or amount) of remittances. Distinctive predictions are indicated in square brackets.

[Table 1. Overview of the Empirical Predictions of Remittance Theories]

In an altruistic model of remittances, a migrant's utility function includes the utility of other household members. The migrant remits to improve his or her household's, and as a consequence his or her own, welfare (Agarwal and Horowitz 2002; Banerjee 1984; Johnson and Whitelaw 1974; Lillard and Willis 1997). The altruistic model sets forth a number of key predictions. First, remittances increase with (i) migrants' income in destination (Cox 1987; Cox et al. 1998; Lucas and Stark 1985). Second, remittances decrease with (ii) migrants' distance to origin and (iii) migrants' duration of stay in destination (Funkhouser 1995). These predictions are attributed to declining altruistic inclinations of migrants who are farther and have been away longer ${ }^{5}$. Third, remittances increase with the increasing economic needs of the origin household, captured, for example, by (iv) the number of dependents in the household and (v) the risks to household's income (Lucas and Stark 1985; Massey and Basem 1992). Fourth, remittances decrease with the

are targeted at positively selecting future migrants. The specific empirical predictions of this model, for example, that remittances will "bribe" unskilled migrants in origin, are not testable with the Thai data. Second, I do not report the predictions for the inheritance motive for remittances. This motive implies that migrants remit to assure future inheritances from the household in origin. The predictions of this model are a subset of those of the exchange model, therefore, I include the inheritance-seeking motive within this more general model. Third and finally, I do not indicate relationships that are ambiguous or non-existent.

${ }^{5}$ The predictions follow from Funkhouser's (1995) formal model, which set up a migrant's utility to include the utility of the origin household. In the empirical application of this model, Funkhouser (1995) argued that a migrant who is farther, and has been away longer, would value his or her own utility more than that of the remaining household members, and reduce the frequency or amount of remittances. Although several studies report a decline in remittances with increased distance to origin and duration in destination (e.g.,Durand et al. 1996a; Lowell and de la Garza 2002), they typically attribute these patterns to migrants' reduced intentions to return, rather than their diminished altruistic inclinations. The former explanation is considered in the exchange motive, where a migrant who is farther away is presumed less likely to return, and less likely to send remittances to bargain for inheritances. 
alternative economic resources available to a household such as (vi) a higher income in origin, or (vii) multiple migrants in destination (Agarwal and Horowitz 2002; Funkhouser 1995; Massey and Basem 1992).

In an exchange model of remittances, a migrant remits to buy services, or to secure future inheritances, from other household members (Cox 1987). This model predicts that remittances increase with (i) the amount of inheritable assets in the origin household, and are higher if (ii) the migrant is a potential heir. Remittances are also higher in (iii) the presence of other migrants from the same household, as migrants use these transfers to compete for inheritances (de la Briere et al. 2002; Hoddinott 1994; Lucas and Stark 1985; VanWey 2004). Similar to the altruistic model, the exchange model predicts that remittances increase with (iv) the number of dependents in households, but attributes this pattern to a payment for dependents' care rather than migrants' altruistic inclinations (Lee, Parish and Willis 1994). Also consistent with the altruistic model, the exchange model expects remittances to increase with (v) migrants' income, but to decrease with (vi) migrants' distance to the origin. The former relationship is based on the ability of higher-earning migrants to pay for services (e.g., taking care of assets or children) in origin. The latter rests on the assumption that farther-away migrants are less likely to return, and hence, less likely to bargain for inheritances with remittances. Different than any other model, the exchange model implies that remittances are lower for (vii) highly educated migrants as these migrants are less likely to return home, and thus, less likely to expect services or inheritances from other members of the household. 
The insurance model views remittances as a part of a mutual risk diversification arrangement between the migrant and the household (Rosenzweig 1988; Stark 1991; Stark and Levhari 1982). Because the migrant typically works in a different region, and in a different sector of the economy, his or her earnings provide a hedge against the risks to household's earnings in origin, and vice versa. The insurance model distinctly predicts that remittances increase with (i) risks to migrants' earnings in destination. Similar to the altruistic model, this model implies that remittances increase with (ii) risks to households' earnings in origin (Agarwal and Horowitz 2002; Cox et al. 1998; de la Briere et al. 2002; Foster and Rosenzweig 2001; Lucas and Stark 1985).

The investment model views remittances as a repayment for household's investment in the migrant, for example, in terms of loans to cover costs of education or migration (Cox and Jimenez 1990; Poirine 1997). Thus, the model implies that remittances increase with (i) migrants' education and (ii) migrants' distance to origin, proxies for costs of education and moving to destination, respectively. These predictions, which are specific to the investment model, have been supported empirically in various settings (Ahlburg and Brown 1998; Cai 2003; Cox et al. 1998; Hoddinott 1994; Lillard and Willis 1997; Lucas and Stark 1985; Regmi and Tisdell 2002). Another prediction, common also to the altruistic and insurance models, suggests that remittances increase with (iii) risks to household's income in origin, which create higher incentives to invest in migration. A final prediction, consistent also with the altruistic and exchange models, states that remittances increase with (iv) migrants' income in destination. 
As presented in Table 1, the four models, which suggest different underlying motives for remitting, share several common predictions. Yet, the models make a number of distinctive, and at times opposing, predictions (shown in square brackets), which allow us to discriminate between different explanations of remittance behavior in the Thai setting.

A number of researchers have tested the predictions of multiple remittance models in different settings. Lucas and Stark (1985), the pioneers in this respect, found evidence for the exchange, insurance and investment models in Bostwana. Cox et al. (1998) showed the relevance of the exchange rather than the altruistic model in Peru. Agarwal and Horowitz (2002) declared empirical support for the altruistic rather than the insurance model in Guyana. Similar to de la Briere et al. (2002) in the Dominican Republic, VanWey (2004) found evidence for the exchange and insurance models in Thailand. Regmi and Tisdell (2002) showed support for the exchange and investment motives in Nepal. Foster and Rosenzweig (2001) provided evidence for the altruistic and insurance models in Pakistan and India.

The present study builds on this prior work, and uses Rapoport and Docquier's (2006) unified framework to test the predictions from four models of remittance behavior in the Thai setting. Different than prior work, the study also considers the confounding effect of migrant selectivity. In particular, because remittance behavior is only observed for migrants, a non-random segment of the population, the determinants of remitting are often confounded with the selection process into the migrant sample. 
Few studies to date have considered migrant selectivity in testing models of remittance behavior. Using a small sample of 215 Kenyan households, Hoddinott (1994) was first to employ a Heckman two-stage model of remittances to control for migrant selectivity. Funkhouser (1995) replicated this approach with data from Nicaragua and El Salvador. In recent work, Taylor, Rozelle and de Brauw (2003) and Mora (2005) applied the same model to the cases of China and Mexico, respectively.

The present study builds on the empirical approach of these studies, and presents an integrated analysis of migration and remittance behavior. This analysis takes into account migrant selectivity, and alters our conclusions about the determinants of remittance behavior in Thailand, a setting described in detail below.

\section{Study Setting}

In Thailand, earlier flows out of rural areas consisted mostly of seasonal migrants, who sought to supplement their farm earnings for a few months during droughts that precede the monsoon rains (Phongpaichit and Baker 1996). This seasonal character started to change in the 1980s. From the mid-1980s to mid-1990s, Thailand experienced a steep economic growth, averaging 9 percent per year, due mostly to an increase in export manufacturing (Jansen 1997). This growth created demand for labor in urban centers like Bangkok (Warr and Nidhiprabha 1996). Much of this labor was supplied by rural migrants from the Northeastern part of the country, the region for this study (Chamratrithirong et al. 1995; Mills 1997). 
This period of expansive growth came to an end in the mid-1990s. In 1996, the export growth dropped from over 20 percent to zero, due to increasing competition from China and India. In 1997, the Asian financial crisis hit Thailand, which was followed by a devaluation of the Thai currency, baht, and a brief recession. Unemployment rates increased as a result and rural-urban migration flows began to slow down. Our data capture this boom and bust period of the Thai economy, leading to dramatic changes in migration and remittance flows between rural and urban regions.

\subsection{Data}

The data come from the three waves $(1984,1994$, and 2000) of a longitudinal survey conducted in the Nang Rong district in the historically poor Northeast region of Thailand. ${ }^{6}$ The 1984 wave was a census of 51 villages and included information on individual demographics, household assets and village characteristics. The 1994 wave replicated the 1984 census, following all 1984 respondents still living in the original 51 villages and adding any new residents, and also contained a retrospective life history component that recorded migration, education and labor experiences of all 13 to 35 year-old individuals from age 13 onward. The 1994 wave located and surveyed migrants (who were absent at the time of the village survey) in four major destinations (the provincial capital, Buriram; the regional capital, Korat or Nakhon Ratchasima; Bangkok and the Bangkok Metropolitan Area; and Eastern Seaboard provinces), reaching 70 percent of eligible migrants from 22 of the original 51 villages (Rindfuss et al. 2007). ${ }^{7}$ The final 2000

\footnotetext{
${ }^{6}$ The Nang Rong surveys are conducted by the University of North Carolina and Mahidol University in Thailand. The data and information about the surveys are available at http://www.cpc.unc.edu/projects/nangrong/.

${ }^{7}$ I considered the potential bias due to individuals lost to follow-up. Using an alternative sample from household rosters, which contained information on all migrants based on remaining household members' reports, I re-estimated the three migration-remittance models in Table 4 . All conclusions remained identical except that the exchange model received less support in one indicator (land ownership) in the Heckman estimation with the expanded sample.
} 
survey replicated the 1994 wave, following the 1994 respondents and adding any new residents to the database, and similarly contained a life history as well as a migrant follow-up, component.

Prior research suggested that the full data set from 51 villages does not accurately capture urban migration flows due to missing information from absent migrants (Curran et al. 2005; Garip and Curran 2010). Thus, the present study restricts the analysis to data from 22 villages where migrants were followed-up in four major destinations. The data for the study combine information from the household rosters, life history surveys and village questionnaires. Specifically, in addition to collecting basic demographic information, the 1994 and 2000 household rosters asked each individual about their migration and remittance behavior in the past 12 months. These questions are used to compute the dependent variables for our analysis. The life history surveys in 1994 and 2000 collected retrospective information on annual migration trips, which allow us to compute accumulated migration experience indicators at the individual, household and village level. Finally, the village questionnaires in 1994 and 2000 recorded various village characteristics, which are included as controls. Additional macroeconomic indicators, such as unemployment rates, are obtained from the Thai National Statistics Office.

\subsection{Operational Measures}

The dependent variables for this study are two binary indicators of migration and remittance behavior. Migrants are defined as individuals who were members of their households in 1984 (1994), but moved out of the village two months or more prior to the 1994 (2000) survey. Remitters are defined as migrants who sent money or goods (food, clothing, household items, 
electrical appliances or vehicles) to their households during the 12 months preceding the survey (as reported by the household members in origin). ${ }^{8}$

The following variables, listed in the first column of Table 1, capture the key predictions of the altruistic, exchange, insurance and investment models of remittance behavior in the Thai data. Binary indicators for advanced, secondary and primary schooling measure education. Dummy variables indicating whether a person is the youngest daughter, older daughter or son capture that person's heir status. In a traditional Thai household, the youngest daughter, who often cares for her parents, is the most likely heir. Older daughters are second in line, while sons, who typically move into their wife's household, are the last.

Occupation serves as a proxy for migrant's income. ${ }^{9}$ In Thailand, factory jobs pay the highest salaries on average, followed by service and construction jobs. ${ }^{10}$ The unemployment rate in a migrant's occupation captures the risks to his or her income. The duration of a migrant's last trip provides a measure of his or her degree of separation from the household. The distance of

\footnotetext{
${ }^{8}$ The Nang Rong data also record the amount of remittances, however, this information may be unreliable. I conducted fieldwork in the region in 2005 and observed that most migrants were reluctant to reveal how much remittances they sent. Talking to village leaders, I learned that individuals had strong incentives to hide their income in order to qualify for need-based loans from the Million Baht fund (a discretionary fund of approximately 25,000 US\$ given to each village by the government). Therefore, in this study, I take a conservative approach and focus on the remittance decision rather than the amount.

${ }^{9}$ The data put students and unemployed into the same occupational category, which, combined with farmers, constitute the reference group in our analysis. Students and unemployed individuals are included in the sample as a considerable share of them migrated (18\%) and sent remittances $(9 \%)$. A number of scholars suggested that remittance theories are applicable to this group. VanWey (2004) compared the altruistic and contractual models of remittances in the Nang Rong data and included the students and unemployed in her sample. Piotrowski (2006) studied the effect of social networks on remittances with the Nang Rong data and also included the students and unemployed in his analysis. Similarly, Adams (1989) analyzed the impact of remittances on inequality in Egypt, and relied on a sample containing student migrants. The literature thus justifies the inclusion of the student and unemployed category in analysis, but our key results are also robust to its exclusion (results available upon request). ${ }^{10}$ According to Thailand National Statistics Office (Labor Force Survey, Table 7), manufacturing occupations paid $5,870 \mathrm{baht} / \mathrm{month}$ on average in 2007. The average wages for service workers (employed in private households or hotels/restaurants) and construction workers were $5012 \mathrm{baht} / \mathrm{month}$ and 4,715 baht/month respectively.
} 
migrant's destination to origin is captured roughly with two dummy indicators for Bangkok or Central Provinces (both about $350 \mathrm{~km}$ from Nang Rong) and Northeastern Provinces (about 100 $\mathrm{km})$. The indicator of whether an individual has a child ( $<15$ years old) in the origin household, the total number of children (of women younger than 30) and number of seniors (older than 64) capture the degree of dependency in the household. For each migrant, the number of other migrants from the household captures the degree of competition for future inheritances, or the amount of alternative economic resources available to the household. In its former operationalization, the variable tests a prediction of the exchange model, while in the latter one, it captures a relationship identified by the altruistic model.

Land and cattle, the major household assets in rural Thailand, are lagged to prevent endogeneity with migration and remittance decisions. For both variables, the 2000 (1994) values come from the 1994 (1984) household survey. Prior work identified a nonlinear effect of household assets on migration and remittance propensities in the Thai setting (VanWey 2003; VanWey 2004). To capture this pattern, I create four categories of land ownership (no land, 1-14 rai, 14-31 rai, and more than $31 \mathrm{rai}$; a rai is approximately 0.4 acre) and use the logarithm of cattle owned. Along with land and cattle, the indicators for the number of household members in a non-agricultural occupation (excluding the index individual) ${ }^{11}$ and the number of economic activities (silk weaving, silk worm raising, other cloth weaving, charcoal making), also lagged, proxy a household's income. ${ }^{12}$

\footnotetext{
${ }^{11}$ Non-agricultural occupations include wage positions (e.g., factory or construction worker, teacher, government official) as well as entrepreneurial activities (e.g., shop owner or street vendor), and typically provide higher earnings than agricultural work (e.g., harvesting for pay).

${ }^{12}$ Lagging the wealth (or income) indicators does not solve the endogeneity problem if current migration decisions are correlated with past migration, which affect household wealth in the past, or if there are omitted variables related to both wealth and migration. To test if this is the case, I perform a procedure suggested by (Spencer and Berk 1981). I estimate a model of wealth (for each of the land, cattle, household members in a non-agricultural occupation
} 
The months of water shortage in a year capture the duration of the droughts, which limit agricultural activities and thus pose a risk to the origin household's subsistence or income. (Most agricultural activities are subsistence-oriented.) The presence of a school in the village and the years since the village was electrified both measure the level of development, and thus, the amount of opportunities for investment in the origin village.

Age, marital status, and household size, added as controls, capture basic demographic information. (Sex is already accounted for with the binary indicators for youngest daughter, older daughter or son.) An indicator for migration trips by the individual (obtained from life history data) measures prior migration experiences, which increase the propensities to re-migrate. Indicators for migration trips by household members and villagers (aggregated from individuallevel data) capture the higher likelihood of migration from households and villages with an established history of migration (Garip 2008; Garip and Curran 2010). Proportion of households that receive remittances (among those that have migrants) serves as a proxy for the collective remittance behavior in the village. Finally, a binary indicator for survey year (1994 or 2000) accounts for the change in migration and remitting behavior over time.

\subsection{Descriptive Statistics}

and economic activities indicators) with exogenous regressors (rain shortages, which are likely to affect wealth and income). Then, in the migration equation, I add the residuals from the four wealth equations as extra regressors. The coefficients for the four regressors are jointly insignificant $(\mathrm{F}$-statistic $=1.51, \mathrm{p}=0.20)$, and the null hypothesis that the wealth indicators are orthogonal to the errors cannot be rejected. I repeat this analysis for the remittance equation, and similarly find that the coefficients for the residuals are jointly insignificant (F-statistic $=0.49, \mathrm{p}=$ 0.75). These results suggest that the lagged wealth (and income) indicators can be treated as exogenous to current migration or remittance decisions. Crucially, this treatment does not preclude an association between wealth and past migration or remittances. But this link does not seem to bias our estimates of the effect of lagged wealth on migration or remittances. 
Table 2 displays means for all variables separately for the overall sample, subset of migrants and subset of remitters (among migrants) along with results from difference-of-means tests that compare migrants to non-migrants and remitters to non-remitters. (The means for non-migrants and non-remitters are not shown to conserve space.) Migrants, about 20 percent of the sample, differ significantly $(p<0.05)$ from non-migrants in all variables but the indicators for youngest daughter and migrant trips in the village. Compared to non-migrants, migrants have higher education, are more likely to be sons rather than daughters, and are less likely to have children, but live in households with a higher total number of children, seniors and other migrants. Migrants also live in households that are wealthier in land and cattle, that have more members in a non-agricultural occupation, and that engage in a higher number of economic activities.

Migrants are more likely to come from villages where rainfall has been scarce and development level is low as indicated by the lack of a school or few years since electrification. Migrants are typically younger than non-migrants, less likely to be married, and more likely to belong to larger households. Migrants are also more likely to have prior migration experience themselves, or to live in households where other members do. These comparisons suggest that migrants are a highly selective group in these rural communities, and thus support our intuition that an isolated analysis of remittance behavior in this group alone may lead to biased results.

[Table 2. Sample Characteristics for the Overall Sample, Subset of Migrants and Subset of Remitters]

Remitters, about 70 percent of migrants, are also significantly different from non-remitters in many variables. Remitters are less likely to have advanced education, less likely to be sons, and 
consequently, more likely to be daughters compared to non-remitters. Remitters are more likely to be employed in higher paying factory jobs, and face a higher unemployment rate in destination. Migrants who remit typically spend a longer time away from origin, compared to those who do not, and live in a more distant destination (Bangkok or Central rather than Northeastern provinces). Remitters are more likely to have a child in origin, come from households that have a higher number of children, but lower number of seniors, and medium, rather than high or low, amounts of land. Remitters belong to households where more a higher number of members work in a non-agricultural occupation. Remitters are slightly younger than non-remitters, less likely to be married, and belong to smaller households. They have more prior migration experience and come from villages where a higher proportion of migrant households receive remittances.

\section{Analytic Strategy}

Let the migration and remittance decisions of an individual be represented by two binary dependent variables $y_{1}$ and $y_{2}$. Assume that both of these variables are generated by a probit equation such that:

$$
\begin{aligned}
& y_{1}^{*}=x_{1} \beta_{1}+\varepsilon_{1} \\
& y_{2}^{*}=x_{2} \beta_{2}+\varepsilon_{2}
\end{aligned}
$$

where $y_{j}^{*}$ are unobserved (latent) variables related to the binary dependent variables as follows:

$$
y_{j}=\left\{\begin{array}{l}
1 \text { if } y_{j}^{*}>0 \\
0 \text { if } y_{j}^{*} \leq 0
\end{array} \quad j=1,2\right.
$$


If we assume that the error terms $\varepsilon_{1}$ and $\varepsilon_{2}$ are independent and identically distributed (i.i.d.) standard normal, the probability $\pi_{j}$ of observing a positive outcome is:

$$
\pi_{j}=\Phi\left(x_{j} \beta_{j}\right)
$$

where $\Phi$ is the standard normal cumulative distribution function. The inverse transformation of the above equation, which expresses the linear predictor as a function of the probability, gives rise to two probit models (for $j=1,2$ ).

The conventional approach in the literature models remittances separately from migration using a probit model as in equation (2). A weakness of this approach is that it assumes a priori that the error terms from migration and remittance equations are uncorrelated. Yet, this assumption may be untenable if the unobserved factors that influence migration behavior are also related to the remittance outcome. In that case, migration process generates a non-random sample of individuals for observing remittances, and consequently, the standard probit estimation leads biased estimates.

This issue of sample selection poses a serious methodological problem with potentially dramatic consequences for substantive conclusions. When a portion of the data is systematically excluded, both external and internal validity of the conclusions are threatened (Berk 1983). For example, imagine a community where only rich individuals can afford to migrate due to high costs of migrating, and all individuals are equally likely to remit once they migrate. If we estimate a model of remittances on a sample of migrants only, we will underestimate the effect of wealth, concluding that it is not important for remitting behavior. However, in the overall population, wealth is the most important characteristic influencing remittances, as it determines whether a 
person will be a migrant in the first place. Excluding non-migrants from our sample in this case will compromise the external validity of our conclusions.

Internal validity is also vulnerable to sample selection even when researchers seek to make statements on the censored population alone, migrants in our case. Assume that families send more responsible sons or daughters as migrants, and these individuals are more likely to command greater earnings, and send remittances. This unobserved characteristic affects both migration and remittance behavior, and leads to biased conclusions about the latter, which is problematic even if one's interest lies only on migrants (Berk 1983; Heckman 1979).

We can account for the sample selection bias by employing a variant of Heckman's (1979) twostep selection model. Because in our case both the selection and outcome equations have binary dependent variables, we end up with a censored bivariate probit specification which has previously been used by Boyes, Hoffman and Low (1989), Dubin and Rivers (1989), Reed (2000), and van de Ven and van Praag (1981). Note that if the two equations are indeed correlated, this specification corrects for sample selection bias in the remittance equation. Conversely, if there is no correlation, then this procedure is identical to estimating the two equations separately. By observing the magnitude and significance of the correlation term, we can determine whether sample selection indeed biases our results. ${ }^{13}$

\footnotetext{
${ }^{13}$ In the classical Heckman (1979) example, one observes wages for women who are employed. Employed women constitute a nonrandom sample, if, for example, more productive women self-select into employment based on their higher expectations about wages. In that case, focusing on the censored sample alone leads us to overestimate the wages in the overall population. One can extend this analogy to remittances: more productive individuals may selfselect into migration behavior based on their expectations about earnings in destination, and consequently, their potential for sending remittances to origin. But one can also imagine the opposite situation, where less productive individuals self-select into migration due to the lack of opportunities in origin. The first case of positive selection leads us to overestimate remittances in the overall population, and the second case of negative selection leads us to
} 
The censored bivariate probit model employs the same structure displayed in (1)-(2), but recognizes that $y_{2}$ is observed only if $y_{1}=1$, and that error terms $\left(\varepsilon_{1}, \varepsilon_{2}\right)$ may have a non-zero correlation $(\rho)$. This specification leads to the following log-likelihood function for sample of $N$ observations (Meng and Schmidt 1985; van de Ven and van Praag 1981):

$\ln L=\sum_{i=1}^{N}\left\{y_{i 1} y_{i 2} \ln \Phi_{2}\left(z_{i 1}, z_{i 2}, \rho\right)+y_{i 1}\left(1-y_{i 2}\right) \ln \left[\Phi\left(z_{i 1}\right)-\Phi_{2}\left(z_{i 1}, z_{i 2}, \rho\right)\right]+\left(1-y_{i 1}\right) \ln \left[1-\Phi\left(z_{i 1}\right)\right]\right\}$

where $\Phi_{2}$ is the standard bivariate normal distribution function, $\Phi$ is the standard normal distribution function and $z_{i j}=x_{i j} \beta_{j}$. Note that the first and second terms on the right-hand side relate to migrants that remit and do not remit respectively. The third term relates to the censored individuals that do not become migrants.

\subsection{Using Geographic Variation as an Instrument for Migration}

To manage a censored sample, the Heckman model calls for an independent variable that influences migration (selection), but does not directly affect remittances (outcome), nor is it correlated with the unobservables affecting remittances. This variable, known as an instrument or an exclusion restriction, is included in the migration equation, but can be legitimately excluded from the remittance equation. Although an instrument is not strictly required, if the set of regressors are identical for the selection and outcome equations, the identification is obtained solely through the nonlinear functional form of selection (Little 1985) and the estimation is poor due to high multicollinearity (Achen 1986; Berk 1983).

underestimate them. By observing the sign and magnitude of the correlation term (rho), we can assess the plausibility of each scenario. 
Few studies have used the Heckman specification to correct for migrant selectivity in a model of remittance behavior. These studies either did not specify an instrument (e.g., Funkhouser 1995; Hoddinott 1994), or used one without proper empirical justification. In the latter group, Taylor et al. (2003) and Mora (2005), for example, both used an indicator for community migration prevalence to satisfy the exclusion restriction. But, migration prevalence is likely to be related to other factors, such as development level or income opportunities in a community, which may also affect remittance behavior. Since there is no attempt to discard such possibilities, it is not clear that the identification is credible in these applications.

Environmental or geographic variables have been used as instruments in various applications, based on the underlying assumption that individuals have no control over the characteristics of the region in which they live in (Moffitt 2003). In the Thai case, the distance to the district center, Nang Rong, to which migrants need to travel to reach urban destinations, may be a potential instrument. ${ }^{14}$ Individuals who live in a village far from the district face higher travel costs, and thus may have lower propensities to migrate especially if their families have limited financial resources. $^{15}$

\footnotetext{
${ }^{14}$ One objection to distance as an instrument is that omitted characteristics may be related to both residential choices and subsequent migration decisions. Distance, in that case, may not be assumed exogenous to migration behavior. Two analyses consider this possibility. The first introduces village-level indicators to the migration model (the proportion of households growing cassava and sugar cane - the crops that create agricultural jobs - and the presence of a nearby factory) capturing the conditions that may have attracted settlers to a village initially, and may have affected their migration decisions later on. The second analysis estimates the migration model on a sample of individuals born in their village of residence (who, as a result, have not chosen that residence area themselves). The estimated effect of distance on migration remains robust in both analyses (results available upon request), which provide no evidence against the assumption that distance is an exogenous determinant of migration.

${ }^{15}$ Individuals' proximity to the final destination (e.g., Bangkok) is a more accurate measure of travel costs. But this measure is only available for migrants, therefore, cannot be used as an instrument for the migration decision.
} 


\subsection{Establishing the Relevance of Time to District as an Instrument}

To check this basic insight, I employ a descriptive analysis suggested by Card (1993). I split the 22 villages into two equal groups based on the time it takes to get to the Nang Rong district. A village is considered 'far' if it takes 45 minutes or more to Nang Rong, and 'close' otherwise. I fit a probit model of migration behavior to a subset of individuals who live in far villages. This model includes all the independent variables used in later analysis, but deliberately excludes the indicator for time to district. Thus, I try to attribute the migration behavior of individuals in far villages, who, presumably, are at a disadvantage, to other variables, balancing the scales against finding an independent effect of time to district. Using the estimates from this model, I compute predicted migration probabilities for the whole sample, and divide the sample into four groups based on the quartiles of the predicted migration probabilities.

[Figure 1. Odds Ratio of Migrating in Close vs. Far Villages across Quartiles of Predicted Migration Probabilities]

For each quartile, Figure 1 plots the odds ratio of migrating in close versus far villages. Odds ratio is defined as

$$
\frac{p_{C} /\left(1-p_{C}\right)}{p_{F} /\left(1-p_{F}\right)}
$$

where $p_{C}$ and $p_{F}$ are the proportion of migrants in the close and far villages respectively.

In the lowest quartile of predicted migration, for individuals in close villages, the odds of migration are 3 times as large as those in far villages. In the three higher quartiles, by contrast, distance to district has a modest effect. In the second quartile, for example, the odds ratio is 1.6, meaning that for individuals who live close to the district the odds of migration are 60 percent 
higher compared to those who live farther. In the third and fourth quartiles, the odds ratio drops to 1.3 and 1.1 respectively, suggesting a smaller advantage for individuals in close villages over

those in far ones. These patterns suggest that time to district has a significant effect on migration, and this effect is most pronounced for individuals with the lowest propensities to migrate. As an alternative check for instrument validity, I tested for weak instruments by excluding the distance indicators from the migration model. The resulting F-statistic was 14.11(df=11.913), more than the lower bound of 10 required to reject the hypothesis of weak instruments (Staiger and Stock 1997).

\subsection{Establishing the Exogeneity of Time to District as an Instrument}

For time to district to serve as a legitimate instrument, it must influence individuals' migration propensities, but exert no direct effect on their remittance behavior. While the former condition of relevance is easily demonstrated, as in the analysis above, the latter condition of exogeneity is not directly testable. Following a strategy used by Card (1993), however, we can establish its feasibility.

[Table 3. Estimated Marginal Effect of Time to District on Migration and Remittances]

Table 3 presents estimates from five probit models of migration and remittance behavior. Column (1) shows the marginal effects of time to district (in hours) and its squared term on the propensity to migrate. The results suggest a nonlinear pattern. The likelihood of migration is higher in villages that are at a middle-range distance from the district (and highest in villages that are about 45 minutes away) compared to those that are very near. This pattern, observed in other settings as well (Fuchs-Schuendeln and Schuendeln 2009), is attributable to commuters: 
individuals living close to the district can commute to work instead of having to migrate to an urban destination. Column (2) shows the marginal effects for the distance indicators when demographic, household and village characteristics are controlled for. The effects become slightly smaller compared to those in the first column, but retain their sign and significance.

Columns (3)-(5) show the marginal effects for the distance indicators in three probit models that gradually introduce controls. In all specifications, the marginal effects remain small and insignificant. Distance to district does not seem to affect remittance behavior directly. This result is consistent with the qualitative observations from my fieldwork in the region. ${ }^{16}$ In particular, the majority of the migrants $(n=52)$ and household members $(n=58)$ in my sample indicated sending or receiving remittances via postal services. Given this pattern, one does not expect distance to directly affect remittance behavior, as confirmed by the results in Table 3 . These results, however, are not sufficient to claim that distance is exogenous to remittances. Specifically, distance, if correlated with the unobserved determinants of remittance behavior, may still influence this behavior indirectly (which may not be observed when examining direct correlations). For example, distance may be correlated with the frequency of visits home, which may influence migrants' likelihood of remitting. Or, distance to district may be associated with having better institutions in the village, which may in turn be correlated with the propensity to remit. To take these patterns into account, I included a measure of migrants' trips to destination, which also captures the number of trips back home. I also included indicators for village

\footnotetext{
${ }^{16}$ I conducted 24 focus group interviews, with the participation of 158 individuals, in 8 of the 22 Nang Rong survey villages in November 2005. In each village, I consulted with village headmen to identify potential participants for three focus groups: (1) village leaders (village headman and village committee members), (2) migrant sending household members, and (3) return migrants. Focus groups consisted of six to eight participants, typically equal number of men and women, who discussed the motivations for, and the consequences of, migration and remittance behavior.
} 
institutions, like temples or factories, which obtained insignificant marginal effects across all specifications (not shown). These indicators captured some of the pathways (other than migration) through which distance to district and remittances may be correlated, but there may be others we do not account for. To consider this possibility, which cannot be discarded entirely, I employ an alternative specification.

\subsection{An Alternative Specification}

If distance to district indeed proxies costs of migrating, and not the unobservable factors related to remittance behavior, its effect should be less detrimental on the migration propensities of individuals who live in wealthier households. Thus, an interaction between distance and household wealth should exert a significant effect on the propensity to migrate. Using this interaction term as an instrument, we can include distance in both migration and remittances models, and thus relax the assumption that distance is exogenous to remittances. The maintained assumption is that the direct effect of distance on remittances does not vary by households' wealth status. The results from this alternative specification (available upon request) are similar to those from one where distance alone is the instrument. The latter results are discussed in detail below.

\section{Results}

Table 4 displays the estimates from three empirical specifications to model migration and remittance behavior: (i) a probit model of migration, (ii) a probit model of remittances estimated on a sample of migrants (isolated approach) and (iii) a censored probit model of migration and 
remittances estimated on the entire sample (integrated approach). ${ }^{17}$ The goal is to establish whether the integrated model of remittances, which takes into account migrant selectivity, changes our conclusions about the determinants of remittance behavior in the Thai setting. (In both the probit and censored probit models of remittances, I present the marginal effect of each indicator on the conditional probability of remitting given migration. Using the latter model, one could also compute the marginal effects of the indicators on the joint probability of migrating and remitting.)

[Table 4. Estimated Marginal Effects of Individual, Household and Village Characteristics on Migration and Remittances]

\subsection{Migration}

The first column in Table 4 presents the marginal effects estimated in the migration model. In Thailand, higher paying factory jobs require a high school diploma. As a result, individuals with secondary or advanced education in our sample are more likely to migrate compared to those with primary education or less. The adult children in the household have a higher propensity to migrate compared to other members of the household. Among the adult children, older daughters and sons are more likely to migrate than the youngest daughters, who are often responsible for caring for their parents in their old age.

In Thai families, parents often live with their adult children and take on the task of raising their grandchildren. Thus, in our sample, while having a child decreases the odds of migration, the number of seniors increases the likelihood that an individual will migrate. The total number of young children in the household has no effect on migration. Having other migrants in the

\footnotetext{
${ }^{17}$ In all models, the standard errors are adjusted for clustering at the household level.
} 
household, who potentially provide information about or help with migrating, also increases an individual's propensity to migrate.

Compared to individuals in landless households, those living in households with moderate amounts of land (1-14 rai or 14-31 rai) are more likely to migrate. This nonlinear pattern, observed in other settings as well (Massey, Goldring and Durand 1994), suggests that migrants belong to households that are sufficiently wealthy to afford the costs of migration, but not so wealthy to find migration unattractive. Individuals' likelihood of migrating decreases with the $\log$ of cattle their household owns potentially because cattle ownership signifies employment opportunities, as well as a form of wealth, in the origin, which provide an alternative to migration (VanWey 2003).

Individuals' propensity to migrate does not change with the household's income, measured roughly with the number of members in a non-agricultural occupation and the number of economic activities, but increases with the risks to that income, proxied by the months of water shortage. Individuals are less likely to migrate if their village has a school, but more likely to migrate if their village is a moderate distance from the district, as explained in detail above.

Propensity to migrate increases with age, but decreases with its squared term (reaching its maximum at the age of 24), is lower for married individuals, but higher for those living in large households. The likelihood of migration increases with the prior migration trips of an individual and also with the prior trips of the members of his or her household or village, who provide the information or support required for migrating. Finally, the likelihood of migration is lower in 
2000, compared to 1994, reflecting the declining rural-urban flows in Thailand in the aftermath of the 1997 Asian financial crisis.

\subsection{Remittances}

The marginal effects described above characterize the selectivity of rural-urban migration in Thailand. The remaining analysis describes the implications of this selectivity for the determinants of remittances. I begin with the estimates from the probit model (isolated approach) displayed in the second column, and then compare those to the estimates from the selectivitycorrected Heckman model (integrated approach) displayed in the third column. (In the latter model, I present the marginal effects of each indicator on the conditional probability of remitting given migration.) In the censored probit model, we present the marginal effects of each indicator on the conditional probability of remitting given migration. Put differently, we evaluate the)

In interpreting these results, similar to prior work (Rapoport and Docquier 2006), I assume the following: (i) an estimate provides evidence for a theory if it is both statistically significant and has a sign consistent with a prediction of that theory (displayed in Table 1); (ii) an estimate provides evidence against a theory if it is significant, but has a sign opposite to that expected in that theory; (iii) an estimate provides no evidence for or against a theory if it is not significant. Comparing the relative magnitude of the standardized estimates, I evaluate the relative strength of the evidence for (or against) each theory.

In the probit model, the propensity to remit decreases with education, and is higher for the daughters compared to the other members of the household. These patterns provide distinctive 
evidence for the exchange model which attributes a higher likelihood of remittances to migrants who are less educated, hence more likely to return to the origin, and to those who are heirs to future inheritances, the daughters in the Thai case.

The propensity to remit is highest for migrants in factory jobs, followed by those in construction or service, compared to farmers, students or unemployed. These categories are roughly in descending order of income. Thus, migrants with a higher income are more likely to remit in the Thai setting confirming a prediction shared by the altruistic, exchange and investment models.

The likelihood of remitting declines with the unemployment rate in destination. This pattern contradicts a distinct prediction of the insurance model, which attributes a higher likelihood of remitting to migrants who face risks to their income in destination. Thus, the pattern provides evidence against the insurance model.

The propensity to remit increases with migrants' length of stay in destination, contradicting a prediction of the altruistic model, which expects declining remittances from migrants who have been away longer. The pattern thus provides evidence against the altruistic model.

Migrants in Bangkok or Central provinces, which are about $350 \mathrm{~km}$ to Nang Rong, are more likely to remit than those in more proximate locations. This pattern provides evidence for the investment model, which distinctly predicts higher remittances from migrants in farther away locations, presumably, due to higher costs borne by families of those migrants to finance the migration. 
Migrants with a child in the origin are more likely to remit. This finding provides evidence for the exchange model, which posits remittances to be a repayment for the childcare services received in the origin, and also for the altruistic model, which expects remittances to increase with the increasing economic needs of the origin household.

Other patterns identified with control variables are as follows: The likelihood of remitting increases with age, but decreases with its squared term (peaking at the age of 32) and is lower for married individuals. The likelihood of remitting increases with the proportion of migrants who remit in the village and is higher in 2000 compared to 1994.

A number of these patterns, shown in boldface in the third column of Table 4, change in the integrated approach, which uses a Heckman specification to correct for migrant selectivity. First, migrants' education, which decreases the propensity to remit in the probit model, has no significant effect in the Heckman model. Thus, the pattern, which provides evidence for the exchange model in an isolated analysis of remittances, disappears in the integrated analysis of migration and remittances.

Second, migrants' duration in destination, which increases their propensity to remit in the probit model, is not significant in the Heckman estimates. As a result, the evidence against the altruistic model, significant in the isolated approach, is absent in the integrated one. Third, migrants' distance to origin, which increases their likelihood of remitting according to the probit estimates, 
has no effect in the Heckman model. The evidence for the investment model, suggested by the isolated analysis, once again, disappears in the integrated analysis.

Fourth, having a child in the origin household, which increases the probability of remitting in the probit model, has no significant effect in the Heckman specification. The former pattern, taken as evidence for both the altruistic and exchange motives in the isolated analysis, disappears in the integrated analysis.

Fifth, the number of migrants in the household, which has no effect on the probability of remitting in the probit model, has a positive effect in the Heckman model. Similarly, having moderate amounts of land (1-14 rai or 14-31 rai), which has no effect on remittances in the probit model, obtain positive marginal effects in the Heckman estimates. Compared to the isolated approach, as a result, the integrated analysis provides stronger evidence for the exchange model, which predicts a higher likelihood of remittances in the presence of inheritable assets, such as land, or other migrants from the same household, who might be competing for these assets.

Sixth, and finally, the estimate of rho $(\rho)$, the correlation between the errors of the migration and remittance equations, which is assumed to be zero in the isolated probit model, is positive $(0.622)$ and statistically significant $(p<0.05)$ in the selection-corrected Heckman model. Substantively, the positive sign suggests that the unobserved factors that increase individuals' propensity to migrate also increase their prospects for sending remittances. Statistically, the significant estimate establishes that migration and remittance behavior are correlated in the Thai 
setting. Ignoring this correlation, as in the isolated model of remittances, leads to biased conclusions about the determinants of remittance behavior.

Comparing the relative magnitude of the statistically significant marginal effects in the selectioncorrected model allows us to assess the relative strength of the support for each remittance theory. Among the binary measures, heir status indicators obtain the largest effects $(0.197$ for youngest daughter), followed by dummies for migrants' occupation in destination ( 0.185 for factory worker) and land ownership in origin (0.059 for owning 1-14 rai of land). To compare the relative effects of binary and continuous measures, I use the marginal effect of a change in the latter from its minimum to maximum value. (The ordering is identical if I compare the marginal effect of a standard-deviation change in all indicators.) The unemployment rate obtains a marginal effect of $-0.127(=-0.045 \times(3.51-0.71))$, while the number of migrants in household has an effect of $0.167(=0.028 \times(6-0))$. Considering the relative magnitudes of these estimates, the evidence for the exchange motive (provided by all the above indicators) is the strongest, followed by the support for the investment model (suggested by the large and positive effect of higher-paying occupations). The evidence against the insurance model (given by the negative effect of the unemployment rate) is slightly smaller in magnitude. The evidence for the altruistic model (provided by the positive coefficients of higher-paying occupations) is comparable in magnitude to the evidence against that model (suggested by the positive coefficient of the number of migrants).

\section{Conclusion}

Most empirical work models migration and remittance behavior separately, treating them as independent processes. Because remittances are observed for migrants only, a non-random 
sample of the population, and the unobserved characteristics related to being a migrant are likely to also affect remittance behavior, the empirical estimates from prior studies may be subject to selection bias. To address this problem, this study proposes an integrated empirical approach, and models migration as a mechanism for selection in a censored bivariate probit specification of remittance behavior.

Compared to an isolated analysis of remittances, the integrated approach leads to different conclusions about the determinants of remittance behavior in the Thai internal migration setting. To the extent that these determinants correspond to different remittance motivations, as presented in the unifying framework of Rapoport and Docquier (2006), the integrated analysis also alters the empirical evidence for and against each motivation.

Specifically, in the Thai settings, by moving from an isolated analysis of remittances to an integrated one, (i) the evidence for the exchange motivation, where remittances are in return for assets or services migrants expect from households, becomes weaker in two indicators, but stronger in two others; (ii) the evidence for the investment motivation, where remittances are a repayment for past loans from households, disappears, as does (iii) the evidence both for and against the purely altruistic motivation for remittances.

The patterns identified in the isolated and integrated models carry different macro-level implications. In the integrated analysis, the higher remittance propensity to households with moderate land (compared to the landless) provides support for the exchange motivation. This pattern, not detected in the isolated analysis, implies a potential shift in the distribution of 
income or wealth in the origin community. In particular, remittance flows to households with moderate land is likely to allow these households to acquire more land, and approach the level of the wealthiest. But this equalizing effect is counteracted by the growing gap between the moderate-land households and the landless, potentially further marginalizing the latter, and leading to a more unequal overall distribution of wealth in the origin community. In recent work, Garip (2012) compared household wealth data from 1994 and 2000 household rosters in the Nang Rong data, and found evidence for the former, equalizing, effect of remittances.

In sum, the findings suggest that migration and remittance behavior are interrelated, and any analysis of remittance behavior should control for the selectivity of migration. The findings also suggest that the mixed empirical results on remittance behavior in the literature may be attributable, at least partially, to a failure to control for migrant selectivity. Using the empirical strategy described here, and the unified theoretical framework provided by Rapoport and Docquier (2006), future research can control for the differential selectivity in different contexts, and consider the empirical predictions from multiple theories of remittance behavior. This new direction may allow us to accumulate coherent and comparable findings about remittance behavior from various settings. 


\section{References}

Achen, C. 1986. The statistical analysis of quasi-experiments: University of California Press.

Adams, R. 1989. "Worker remittances and inequality in rural Egypt." Economic Development and Cultural Change 38(1):45-71.

Agarwal, R.and A.W. Horowitz. 2002. "Are international remittances altruism or insurance? Evidence from Guyana using multiple-migrant households." World Development 30(11):20332044.

Ahlburg, D.and R. Brown. 1998. "Migrants' intentions to return home and capital transfers: A study of Tongans and Samoans in Australia." Journal of Development Studies 35(2):125-151.

Banerjee, B. 1984. "The probability, size and uses of remittances from urban to rural areas in India." Journal of Development Economics 16(3):293-311.

Berk, R. 1983. "An introduction to sample selection bias in sociological data." American Sociological Review 48(3):386-398.

Boyes, W., D. Hoffman, and S. Low. 1989. "An econometric analysis of the bank credit scoring problem." Journal of Econometrics 40(1):3-14.

Cai, Q. 2003. "Migrant remittances and family ties: a case study in China." International Journal of Population Geography 9(6):471-483.

Card, D. 1993. "Using geographic variation in college proximity to estimate the return to schooling." NBER working paper.

Carling, J. 2008. "The determinants of migrant remittances." Oxford Review of Economic Policy 24(3):581-598.

Chamratrithirong, A., K. Archavanitkul, K. Richter, P. Guest, V. Thongthai, W. Bonochalaksi, and N. Piriyanthamwong. 1995. National Migration Survey of Thailand. Nakonpathom, Thailand: Institute for Population and Social Research, Mahidol University.

Cox, D. 1987. "Motives for private income transfers." The Journal of Political Economy 95(3):508-546.

Cox, D., Z. Eser, and E. Jimenez. 1998. "Motives for private transfers over the life cycle: An analytical framework and evidence for Peru." Journal of Development Economics 55(1):57-80.

Cox, D.and E. Jimenez. 1990. "Achieving Social Objectives through Private Transfers: A Review." The World Bank Research Observer 5(2):205-218.

Curran, S., F. Garip, C. Chung, and K. Tangchonlatip. 2005. "Gendered migrant social capital: Evidence from Thailand." Soc. F. 84:225. 
de la Briere, B., E. Sadoulet, A. De Janvry, and S. Lambert. 2002. "The roles of destination, gender, and household composition in explaining remittances: an analysis for the Dominican Sierra." Journal of Development Economics 68(2):309-328.

Dubin, J.and D. Rivers. 1989. "Selection bias in linear regression, logit and probit models." Sociological Methods and Research 18(2):360-390.

Durand, J., W. Kandel, E.A. Parrado, and D.S. Massey. 1996a. "International Migration and Development in Mexican Communities." Demography 33(2):249-264.

Durand, J., E. Parrado, and D. Massey. 1996b. "Migradollars and development: a reconsideration of the Mexican case." International Migration Review 30(2):423-444.

Foster, A.and M. Rosenzweig. 2001. "Imperfect commitment, altruism, and the family: Evidence from transfer behavior in low-income rural areas." Review of Economics and Statistics 83(3):389-407.

Fuchs-Schuendeln, N.and M. Schuendeln. 2009. "Who Stays, Who Goes, Who Returns? EastWest Migration within Germany since Reunification." Economics of Transition 17(3):703-738.

Funkhouser, E. 1995. "Remittances from International Migration: A Comparison of El Salvador and Nicaragua." The Review of Economics and Statistics 77(1):137-146.

Garip, F. 2008. "Social capital and migration: How do similar resources lead to divergent outcomes?" Demography 45(3):591-617.

—. 2012. "The Impact of Migration and Remittances on Wealth Accumulation and Distribution in Rural Thailand." in Weatherhead Center for International Affairs Working Paper: Harvard University.

Garip, F.and S. Curran. 2010. "Increasing Migration, Diverging Communities: Changing Character of Migrant Streams in Rural Thailand." Population Research and Policy Review 29(5):659-685.

Heckman, J. 1979. "Sample selection bias as a specification error." Econometrica: Journal of the econometric society 47(1):153-161.

Hoddinott, J. 1994. "A Model of Migration and Remittances Applied to Western Kenya." Oxford Economic Papers 46(3):459-476.

Jansen, K. 1997. External Finance in Thailand's Development: An Interpretation of Thailand's Growth Boom. New York, NY: St Martin's Press.

Johnson, G.and W. Whitelaw. 1974. "Urban-rural income transfers in Kenya: an estimatedremittances function." Economic Development and Cultural Change 22(3):473-479.

Jones, R.C. 1998. "Remittances and Inequality: A Question of Migration Stage and Geographic Scale." Economic Geography 74(1):8-25. 
Lauby, J.and O. Stark. 1988. "Individual migration as a family strategy: Young women in the Philippines." Population Studies 42(3):473-486.

Lee, Y., W. Parish, and R. Willis. 1994. "Sons, daughters, and intergenerational support in Taiwan." American Journal of Sociology 99(4):1010-1041.

Lillard, L.and R. Willis. 1997. "Motives for intergenerational transfers: Evidence from Malaysia." Demography 34(1):115-134.

Little, R.J. 1985. "A Note about Models for Selectivity Bias." Econometrica 53(6):1469-1474.

Lowell, B.L.and R.O. de la Garza. 2002. "The development role of remittances in U.S. Latino communities and Latin America." Pp. 3-27 in Sending Money Home: Hispanic Remittances and Community Development, edited by R. de la Garza and B.L. Lowell. Lanham, MD: Rowman and Littlefield.

Lucas, R.and O. Stark. 1985. "Motivations to remit: Evidence from Botswana." The Journal of Political Economy:901-918.

Massey, D.and L. Basem. 1992. "Determinants of savings, remittances, and spending patterns among US migrants in four Mexican communities." Sociological Inquiry 62(2):185-207.

Massey, D.S., L. Goldring, and J. Durand. 1994. "Continuities in Transnational Migration: An Analysis of Nineteen Mexican Communities." American Journal of Sociology 99(6):1492-1533.

Meng, C.and P. Schmidt. 1985. "On the cost of partial observability in the bivariate probit model." International Economic Review 26(1):71-85.

Mills, M. 1997. "Contesting the margins of modernity: Women, migration, and consumption in Thailand." American Ethnologist 24(1):37-61.

Moffitt, R. 2003. "Causal analysis in population research: An economist's perspective." Population and Development Review 29(3):448-458.

Mora, J.J. 2005. "The Impact of Migration and Remittances on Distribution and Sources of Income." United Nations Population Division Working Paper.

Phongpaichit, P.and C. Baker. 1996. Thailand's Boom! New South Wales, Australia: Allen and Unwin.

Piotrowski, M. 2006. "The Effect of Social Networks at Origin Communities on Migrant Remittances: Evidence from Nang Rong District." European Journal of Population / Revue Europienne de Demographie 22(1):67-94.

Poirine, B. 1997. "A theory of remittances as an implicit family loan arrangement." World Development 25(4):589-611. 
Rapoport, H.and F. Docquier. 2006. "The economics of migrants' remittances." Handbook on the Economics of Giving, Reciprocity and Altruism 2:1135-1198.

Ratha, D.and Z. Xu. 2008. Migration and Remittances Factbook 2008. Washington, D.C.: World Bank Publications.

Reardon, T. 1997. "Using evidence of household income diversification to inform study of the rural nonfarm labor market in Africa." World Development 25(5):735-747.

Reed, W. 2000. "A unified statistical model of conflict onset and escalation." American Journal of Political Science 44(1):84-93.

Regmi, G.and C. Tisdell. 2002. "Remitting behaviour of Nepalese rural-to-urban migrants: Implications for theory and policy." Journal of Development Studies 38(3):76-94.

Rempel, H.and R. Lobdell. 1978. "The role of urban-to-rural remittances in rural development." Journal of Development Studies 14(3):324-341.

Rindfuss, R., T. Kaneda, A. Chattopadhyay, and C. Sethaput. 2007. "Panel studies and migration." Social Science Research 36:374-403.

Rosenzweig, M. 1988. "Risk, implicit contracts and the family in rural areas of low-income countries." The Economic Journal 98(393):1148-1170.

Russell, S. 1986. "Remittances from international migration: a review in perspective." World Development 14(6):677-696.

Sana, M. 2005. "Buying membership in the transnational community: migrant remittances, social status, and assimilation." Population Research and Policy Review 24:231-261.

Spencer, D.F.and K.T. Berk. 1981. "A Limited Information Specification Test." Econometrica 49:1079-1085.

Staiger, D.and J.H. Stock. 1997. "Instrumental Variables Regression with Weak Instruments." Econometrica 65(3):557-586.

Stark, O. 1991. The migration of labor. Cambridge, MA: Basil Blackwell.

Stark, O.and D. Bloom. 1985. "The new economics of labor migration." The American Economic Review 75(2):173-178.

Stark, O.and D. Levhari. 1982. "On migration and risk in LDCs." Economic Development and Cultural Change 31(1):191-196.

Taylor, J. 1999. "The new economics of labour migration and the role of remittances in the migration process." International Migration 37(1):63-88.

Taylor, J., J. Arango, G. Hugo, A. Kouaouci, D. Massey, and A. Pellegrino. 1996. "International migration and national development." Population Index 62(2):181-212. 
Taylor, J., S. Rozelle, and A. De Brauw. 2003. "Migration and Incomes in Source Communities: A New Economics of Migration Perspective from China*." Economic Development and Cultural Change 52:75-101.

van de Ven, W.and B. van Praag. 1981. "The demand for deductibles in private health insurance: A probit model with sample selection." Journal of Econometrics 17(2):229-252.

VanWey, L. 2003. "Land ownership as a determinant of temporary migration in Nang Rong, Thailand." European Journal of Population 19(2):121-145.

VanWey, L.K. 2004. "Altruistic and Contractual Remittances between Male and Female Migrants and Households in Rural Thailand." Demography 41(4):739-756.

Warr, P.and B. Nidhiprabha. 1996. Thailand's Macroeconomic Miracle: Stable Adjustment and Sustained Growth. Washington D.C.: World Bank Press. 


\section{TABLES AND FIGURES}

Table 1. Overview of the Empirical Predictions of Remittance Theories ${ }^{\mathrm{a}}$

Variables

(measures in Nang Rong data)

Migrant's education

(advanced $>$ secondary $>$ primary)

Migrant's heir status

(youngest daughter $>$ older daughter $>$ son)

Migrant's income in destination

(factory $>$ service $>$ construction occupation)

Risks to migrant's income (unemployment rate in occupation)

Migrant's duration in destination (duration of the last trip in years )

Migrant's distance to origin (Bangkok or Central > Northeastern provinces)

Dependents in household (child in origin, total number of children and seniors)

Number of migrants from household (current migrants excluding index migrant)

Household assets in origin (land and cattle)

Household income in origin (land, cattle, members in a non-agricultural occupation, and number of economic activities)

Risks to household subsistence or income (months of water shortage)

Investment opportunities in community (school and years since electrification)

a Expected relationships by each theory are denote distinctive predictions, and empty cells denote no or ambiguous relationship.
Expected Relationship by Theory

Altruism Exchange Insurance Investment

$[-]$

$[+]$

$[+]$

$+$

$+$

$+$

$[+]$

$[-]$

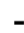

$-$

$[+]$

$+\quad+$

$[-]$

$[+]$

$[-1$

$+\quad+\quad+$

$[+]$ 
Table 2. Sample Characteristics for the Overall Sample, Subset of Migrants and Subset of Remitters

\begin{tabular}{|c|c|c|c|}
\hline Variable & All & Migrants $^{\mathrm{a}}$ & $\mathrm{b}$ \\
\hline \multicolumn{4}{|l|}{ Education } \\
\hline Less than secondary & 0.91 & 0.87 & 0.88 \\
\hline Secondary & 0.04 & 0.06 & 0.06 \\
\hline Advanced & 0.04 & 0.07 & 0.06 \\
\hline \multicolumn{4}{|l|}{ Heir status } \\
\hline Youngest daughter & 0.14 & 0.15 & 0.18 \\
\hline Older daughter & 0.22 & 0.31 & 0.34 \\
\hline Son & 0.30 & 0.40 & 0.37 \\
\hline Other (Head, spouse or other relative) & 0.34 & 0.14 & 0.11 \\
\hline \multicolumn{4}{|l|}{ Destination income (migrants only) } \\
\hline Factory worker & & 0.37 & 0.43 \\
\hline Service worker & & 0.11 & 0.12 \\
\hline Construction worker & & 0.06 & 0.06 \\
\hline Other (Student, unemployed or agricultural worker) & & 0.45 & 0.38 \\
\hline \multicolumn{4}{|l|}{ Risks to destination income (migrants only) } \\
\hline Unemployment rate in occupation & & 1.86 & 1.94 \\
\hline \multicolumn{4}{|l|}{ Duration in destination (migrants only) } \\
\hline Duration of the last trip in years & & 6.71 & 7.05 \\
\hline \multicolumn{4}{|l|}{ Distance to origin (migrants only) } \\
\hline Northeastern provinces $(\sim 100 \mathrm{~km})$ & & 0.32 & 0.27 \\
\hline Bangkok or Central provinces $(\sim 350 \mathrm{~km})$ & & 0.68 & 0.73 \\
\hline \multicolumn{4}{|l|}{ Dependents in household } \\
\hline Individual has a child in origin & 0.15 & 0.03 & 0.03 \\
\hline Number of children (of women $<30$ year old) & 0.58 & 0.78 & 0.81 \\
\hline Number of seniors ( $>64$ year old) & 0.55 & 0.70 & 0.66 \\
\hline \multicolumn{4}{|l|}{ Migrants in household } \\
\hline Number of migrants (excl. index individual) & 0.97 & 1.90 & 1.91 \\
\hline \multicolumn{4}{|l|}{ Household assets in origin } \\
\hline No land & 0.14 & 0.06 & 0.06 \\
\hline Land owned 1-14 rai & 0.29 & 0.31 & 0.33 \\
\hline Land owned 14-31 rai & 0.28 & 0.31 & 0.32 \\
\hline Land owned $>31$ rai & 0.28 & 0.31 & 0.29 \\
\hline Log of cattle owned & 1.18 & 1.27 & 1.25 \\
\hline \multicolumn{4}{|l|}{ Household income in origin } \\
\hline Members in a non-agricultural occupation & 2.35 & 3.64 & 3.72 \\
\hline Number of economic activities (0-3) & 0.29 & 0.37 & 0.35 \\
\hline \multicolumn{4}{|l|}{ Risks to household subsistence or income } \\
\hline Months of water shortage & 1.66 & 1.85 & 1.86 \\
\hline \multicolumn{4}{|l|}{ Investment opportunities in community } \\
\hline Primary or secondary school in village & 0.63 & 0.59 & 0.57 \\
\hline Years since electrification & 12.44 & 11.85 & 11.90 \\
\hline
\end{tabular}


(Table 2, continued)

\begin{tabular}{lccc}
\hline Variable & All & Migrants $^{\mathrm{a}}$ & $\mathrm{b}^{\mathrm{b}}$ \\
\hline Controls & & & \\
$\quad$ Age & 26.22 & 24.77 & 24.58 \\
$\quad$ Married & 0.62 & 0.48 & 0.45 \\
$\quad$ Household size & 7.02 & 8.84 & 8.72 \\
Migration trips by individual & 0.52 & 0.90 & 0.92 \\
Migration trips by household & 0.89 & 1.15 & 1.17 \\
$\quad$ Migration trips in village (per person) & 0.66 & 0.66 & 0.66 \\
$\quad$ Proportion of remitters among migrants in village & 0.66 & 0.66 & 0.67 \\
$\mathrm{~N}$ & 11,938 & 2,697 & 1,835 \\
\hline
\end{tabular}

a Means for migrants and nonmigrants (not shown) differ significantly $(p<.05)$ for all variables except the youngest daughter indicator and migration trips in the village.

Means for remitter and non-remitter migrants (not shown) differ significantly $(\mathrm{p}<.05)$ for all variables except the indicators for secondary education, construction worker, child in origin,

b number of migrants in the household, no land, land owned 14-31 rai, log of cattle owned, months of water shortage, years since electrification, migration trips by household and in village. 
Table 3. Estimated Marginal Effect of Time to District on Migration and Remittances ${ }^{a}$

\begin{tabular}{|c|c|c|c|c|c|c|c|}
\hline \multirow{2}{*}{ Variable } & \multicolumn{4}{|c|}{ Migration } & \multicolumn{3}{|c|}{ Remittances } \\
\hline & (1) & & (2) & & (3) & (4) & (5) \\
\hline Time to district (hours) & $\begin{array}{c}0.85 \\
(0.18)\end{array}$ & $*$ & $\begin{array}{c}0.21 \\
(0.10)\end{array}$ & $*$ & $\begin{array}{c}0.33 \\
(0.41)\end{array}$ & $\begin{array}{c}0.03 \\
(0.51)\end{array}$ & $\begin{array}{l}-0.01 \\
(0.46)\end{array}$ \\
\hline Time to district squared & $\begin{array}{l}-0.57 \\
(0.12)\end{array}$ & $*$ & $\begin{array}{l}-0.13 \\
(0.07)\end{array}$ & $\dagger$ & $\begin{array}{l}-0.27 \\
(0.28)\end{array}$ & $\begin{array}{c}-0.02 \\
(0.35)\end{array}$ & $\begin{array}{c}0.03 \\
(0.32)\end{array}$ \\
\hline $\begin{array}{l}\text { Demographic, household and village } \\
\text { characteristics }\end{array}$ & no & & yes & & no & yes & yes \\
\hline Migrant's characteristics & - & & - & & no & no & yes \\
\hline $\mathrm{N}$ & 11,938 & & 11,938 & & 2,697 & 2,697 & 2,697 \\
\hline $\mathrm{R}^{2}$ & 0.01 & & 0.32 & & 0.002 & 0.06 & 0.11 \\
\hline
\end{tabular}

${ }^{* *} \mathrm{p}<.01,{ }^{*} \mathrm{p}<.05, \dagger \mathrm{p}<0.10$. Standard errors, shown in parentheses, are adjusted for household-level clustering.

a The dependent variable in columns 1 and 2 is whether a person is a migrant in year 1994 or 2000. The dependent variable in columns 3-5 is whether a migrant has sent remittances to his or her household. All models include an indicator for year 2000. 
Table 4. Estimated Marginal Effects of Individual, Household and Village Characteristics on Migration and Remittances ${ }^{a}$

\begin{tabular}{|c|c|c|c|c|c|c|}
\hline \multirow[b]{2}{*}{ Variable } & \multirow{2}{*}{\multicolumn{2}{|c|}{$\frac{\text { Migration }}{\text { (1) }}$}} & \multicolumn{4}{|c|}{ Remittances } \\
\hline & & & \multicolumn{2}{|l|}{ (2) } & \multicolumn{2}{|c|}{$\begin{array}{l}\text { (3) Selection bias } \\
\text { corrected }^{\mathrm{b}}\end{array}$} \\
\hline \multicolumn{7}{|l|}{ Education } \\
\hline Secondary & $\begin{array}{c}0.063 \\
(0.021)\end{array}$ & $* *$ & $\begin{array}{l}-0.019 \\
(0.046)\end{array}$ & & $\begin{array}{c}0.012 \\
(0.026)\end{array}$ & \\
\hline Advanced & $\begin{array}{c}0.093 \\
(0.024)\end{array}$ & $* *$ & $\begin{array}{l}-0.113 \\
(0.041)\end{array}$ & $* *$ & $\begin{array}{l}\mathbf{- 0 . 0 2 8} \\
(0.030)\end{array}$ & \\
\hline \multicolumn{7}{|l|}{ Heir status } \\
\hline Youngest daughter & $\begin{array}{c}0.069 \\
(0.014)\end{array}$ & $* *$ & $\begin{array}{c}0.260 \\
(0.041)\end{array}$ & $* *$ & $\begin{array}{c}0.197 \\
(0.065)\end{array}$ & $* *$ \\
\hline Older daughter & $\begin{array}{c}0.117 \\
(0.016)\end{array}$ & $* *$ & $\begin{array}{c}0.207 \\
(0.038)\end{array}$ & $* *$ & $\begin{array}{c}0.178 \\
(0.051)\end{array}$ & $* *$ \\
\hline Son & $\begin{array}{c}0.092 \\
(0.014)\end{array}$ & $* *$ & $\begin{array}{c}0.063 \\
(0.035)\end{array}$ & $\dagger$ & $\begin{array}{c}0.069 \\
(0.024)\end{array}$ & $* *$ \\
\hline \multicolumn{7}{|l|}{ Destination income (migrants only) } \\
\hline Factory worker & - & & $\begin{array}{c}0.293 \\
(0.064)\end{array}$ & $* *$ & $\begin{array}{c}0.185 \\
(0.082)\end{array}$ & * \\
\hline Service worker & - & & $\begin{array}{c}0.120 \\
(0.041)\end{array}$ & $* *$ & $\begin{array}{c}0.064 \\
(0.039)\end{array}$ & \\
\hline Construction worker & - & & $\begin{array}{c}0.174 \\
(0.067)\end{array}$ & $*$ & $\begin{array}{c}0.098 \\
(0.057)\end{array}$ & $\dagger$ \\
\hline \multicolumn{7}{|l|}{ Risks to destination income (migrants only) } \\
\hline Unemployment rate in occupation & - & & $\begin{array}{l}-0.096 \\
(0.040)\end{array}$ & $*$ & $\begin{array}{l}-0.045 \\
(0.026)\end{array}$ & $\dagger$ \\
\hline \multicolumn{7}{|l|}{ Duration in destination (migrants only) } \\
\hline Duration of the last trip in years & - & & $\begin{array}{c}0.005 \\
(0.002)\end{array}$ & $\dagger$ & $\begin{array}{c}\mathbf{0 . 0 0 2} \\
(0.002)\end{array}$ & \\
\hline \multicolumn{7}{|l|}{ Distance to origin (migrants only) } \\
\hline Bangkok or Central provinces $(\sim 350 \mathrm{~km})$ & - & & $\begin{array}{c}0.059 \\
(0.028)\end{array}$ & $*$ & $\begin{array}{r}\mathbf{0 . 0 2 6} \\
(0.018)\end{array}$ & \\
\hline \multicolumn{7}{|l|}{ Dependents in household } \\
\hline Individual has a child in origin & $\begin{array}{l}-0.087 \\
(0.013)\end{array}$ & $* *$ & $\begin{array}{c}0.222 \\
(0.081)\end{array}$ & ** & $\begin{array}{c}\mathbf{0 . 0 2 0} \\
(0.061)\end{array}$ & \\
\hline Number of children (of women $<30$ year old) & $\begin{array}{l}-0.006 \\
(0.004)\end{array}$ & & $\begin{array}{c}0.004 \\
(0.015)\end{array}$ & & $\begin{array}{r}0.000 \\
(0.007)\end{array}$ & \\
\hline Number of seniors ( $>64$ year old) & $\begin{array}{c}0.008 \\
(0.004)\end{array}$ & $\dagger$ & $\begin{array}{c}0.001 \\
(0.014)\end{array}$ & & $\begin{array}{c}0.003 \\
(0.007)\end{array}$ & \\
\hline
\end{tabular}


(Table 4, continued)

\begin{tabular}{|c|c|c|c|c|c|}
\hline \multirow[b]{2}{*}{ Variable } & \multicolumn{2}{|c|}{ Migration } & \multicolumn{3}{|c|}{ Remittances } \\
\hline & \multicolumn{2}{|c|}{$(1)$} & \multirow[t]{2}{*}{ (2) } & \multicolumn{2}{|c|}{$\begin{array}{l}\text { (3) Selection bias } \\
\text { corrected }^{\mathrm{b}}\end{array}$} \\
\hline \multicolumn{5}{|l|}{ Migrants in household } & \\
\hline Number of migrants (excl. index individual) & $\begin{array}{c}0.079 \\
(0.010)\end{array}$ & $* *$ & $\begin{array}{c}0.001 \\
(0.014)\end{array}$ & $\begin{array}{c}\mathbf{0 . 0 2 8} \\
(0.009)\end{array}$ & $* *$ \\
\hline \multicolumn{6}{|l|}{ Household assets in origin } \\
\hline Land owned 1-14 rai & $\begin{array}{c}0.051 \\
(0.015)\end{array}$ & ** & $\begin{array}{c}0.073 \\
(0.054)\end{array}$ & $\begin{array}{c}\mathbf{0 . 0 5 9} \\
(0.032)\end{array}$ & $\dagger$ \\
\hline Land owned 14-31 rai & $\begin{array}{c}0.032 \\
(0.015)\end{array}$ & $*$ & $\begin{array}{c}0.090 \\
(0.054)\end{array}$ & $\begin{array}{c}\mathbf{0 . 0 6 2} \\
(0.035)\end{array}$ & \\
\hline Land owned $>31$ rai & $\begin{array}{c}0.013 \\
(0.015)\end{array}$ & & $\begin{array}{c}0.041 \\
(0.055)\end{array}$ & $\begin{array}{c}0.027 \\
(0.029)\end{array}$ & \\
\hline Log of cattle owned & $\begin{array}{l}-0.006 \\
(0.004)\end{array}$ & $\dagger$ & $\begin{array}{c}0.000 \\
(0.014)\end{array}$ & $\begin{array}{l}-0.002 \\
(0.007)\end{array}$ & \\
\hline \multicolumn{6}{|l|}{ Household income in origin } \\
\hline Members in a non-agricultural occupation & $\begin{array}{c}0.002 \\
(0.002)\end{array}$ & & $\begin{array}{c}0.005 \\
(0.007)\end{array}$ & $\begin{array}{c}0.003 \\
(0.003)\end{array}$ & \\
\hline Number of economic activities $(0-3)$ & $\begin{array}{l}-0.005 \\
(0.005)\end{array}$ & & $\begin{array}{l}-0.009 \\
(0.017)\end{array}$ & $\begin{array}{l}-0.007 \\
(0.009)\end{array}$ & \\
\hline \multicolumn{6}{|l|}{ Risks to household subsistence or income } \\
\hline Months of water shortage & $\begin{array}{c}0.005 \\
(0.002)\end{array}$ & $\dagger$ & $\begin{array}{l}-0.002 \\
(0.009)\end{array}$ & $\begin{array}{c}0.001 \\
(0.004)\end{array}$ & \\
\hline \multicolumn{6}{|l|}{ Investment opportunities in community } \\
\hline Primary or secondary school in village & $\begin{array}{l}-0.014 \\
(0.008)\end{array}$ & $\dagger$ & $\begin{array}{l}-0.011 \\
(0.026)\end{array}$ & $\begin{array}{l}-0.009 \\
(0.013)\end{array}$ & \\
\hline Years since electrification & $\begin{array}{l}-0.001 \\
(0.001)\end{array}$ & & $\begin{array}{c}0.001 \\
(0.004)\end{array}$ & $\begin{array}{c}0.000 \\
(0.002)\end{array}$ & \\
\hline \multicolumn{6}{|l|}{ Exclusion restriction } \\
\hline Time to district (hours) & $\begin{array}{c}0.210 \\
(0.102)\end{array}$ & $*$ & - & - & \\
\hline Time to district squared & $\begin{array}{l}-0.129 \\
(0.067) \\
\end{array}$ & $\dagger$ & - & - & \\
\hline
\end{tabular}

(continued) 


\begin{tabular}{|c|c|c|c|c|c|c|}
\hline \multirow{3}{*}{$\begin{array}{l}\text { Variable } \\
\text { Controls }\end{array}$} & \multirow{2}{*}{\multicolumn{2}{|c|}{$\frac{\text { Migration }}{(1)}$}} & \multicolumn{4}{|c|}{ Remittances } \\
\hline & & & \multicolumn{2}{|l|}{ (2) } & \multicolumn{2}{|c|}{$\begin{array}{l}\text { (3) Selection bias } \\
\text { corrected }^{\mathrm{b}}\end{array}$} \\
\hline & & & & & & \\
\hline Age & $\begin{array}{c}0.014 \\
(0.004)\end{array}$ & ** & $\begin{array}{c}0.032 \\
(0.014)\end{array}$ & $*$ & $\begin{array}{c}0.021 \\
(0.011)\end{array}$ & $\dagger$ \\
\hline Age-squared/100 & $\begin{array}{l}-0.030 \\
(0.008)\end{array}$ & ** & $\begin{array}{c}-0.050 \\
(0.026)\end{array}$ & $\dagger$ & $\begin{array}{l}-0.036 \\
(0.018)\end{array}$ & * \\
\hline Married & $\begin{array}{l}-0.037 \\
(0.010)\end{array}$ & $* *$ & $\begin{array}{l}-0.140 \\
(0.029)\end{array}$ & $* *$ & $\begin{array}{l}-0.085 \\
(0.037)\end{array}$ & $*$ \\
\hline Household size & $\begin{array}{c}0.012 \\
(0.002)\end{array}$ & ** & $\begin{array}{l}-0.009 \\
(0.005)\end{array}$ & & $\begin{array}{c}0.001 \\
(0.003)\end{array}$ & \\
\hline Migration trips by individual & $\begin{array}{c}0.087 \\
(0.011)\end{array}$ & $* *$ & $\begin{array}{c}-0.012 \\
(0.016)\end{array}$ & & $\begin{array}{c}0.026 \\
(0.011)\end{array}$ & $*$ \\
\hline Migration trips by household & $\begin{array}{c}0.013 \\
(0.005)\end{array}$ & ** & $\begin{array}{c}0.011 \\
(0.016)\end{array}$ & & $\begin{array}{c}0.011 \\
(0.008)\end{array}$ & \\
\hline Migration trips in village (per person) & $\begin{array}{c}0.096 \\
(0.038)\end{array}$ & * & $\begin{array}{c}-0.142 \\
(0.110)\end{array}$ & & $\begin{array}{l}-0.026 \\
(0.064)\end{array}$ & \\
\hline Proportion of remitters among migrants in village & - & & $\begin{array}{c}0.986 \\
(0.152)\end{array}$ & $* *$ & $\begin{array}{c}0.467 \\
(0.250)\end{array}$ & $\dagger$ \\
\hline Year 2000 & $\begin{array}{l}-0.055 \\
(0.014)\end{array}$ & $* *$ & $\begin{array}{c}0.144 \\
(0.081)\end{array}$ & $\dagger$ & $\begin{array}{c}0.039 \\
(0.053)\end{array}$ & \\
\hline$\rho$ & - & & - & & $\begin{array}{c}0.622 \\
(0.290)\end{array}$ & * \\
\hline $\begin{array}{l}\mathrm{N} \\
\mathrm{R}^{2}\end{array}$ & $\begin{array}{c}11,938 \\
0.32\end{array}$ & & $\begin{array}{l}2,697 \\
0.11\end{array}$ & & $\begin{array}{c}2,697 \\
-\end{array}$ & \\
\hline
\end{tabular}
effects that change in sign or significance from column 2 to column 3 are shown in boldface.

a The dependent variable in column 1 is whether a person is a migrant in year 1994 or 2000. The dependent variable in columns 2 and 3 is whether a migrant has sent remittances to his or her household.

b In columns 1 and 2, the specification is a probit model of migration and remittances, respectively. In column 3, the specification is a bivariate probit model of migration and remittances where the exclusion restriction is the distance indicators. 
Figure 1. Odds Ratio of Migrating in Close vs. Far Villages across Quartiles of Predicted Migration Probabilities

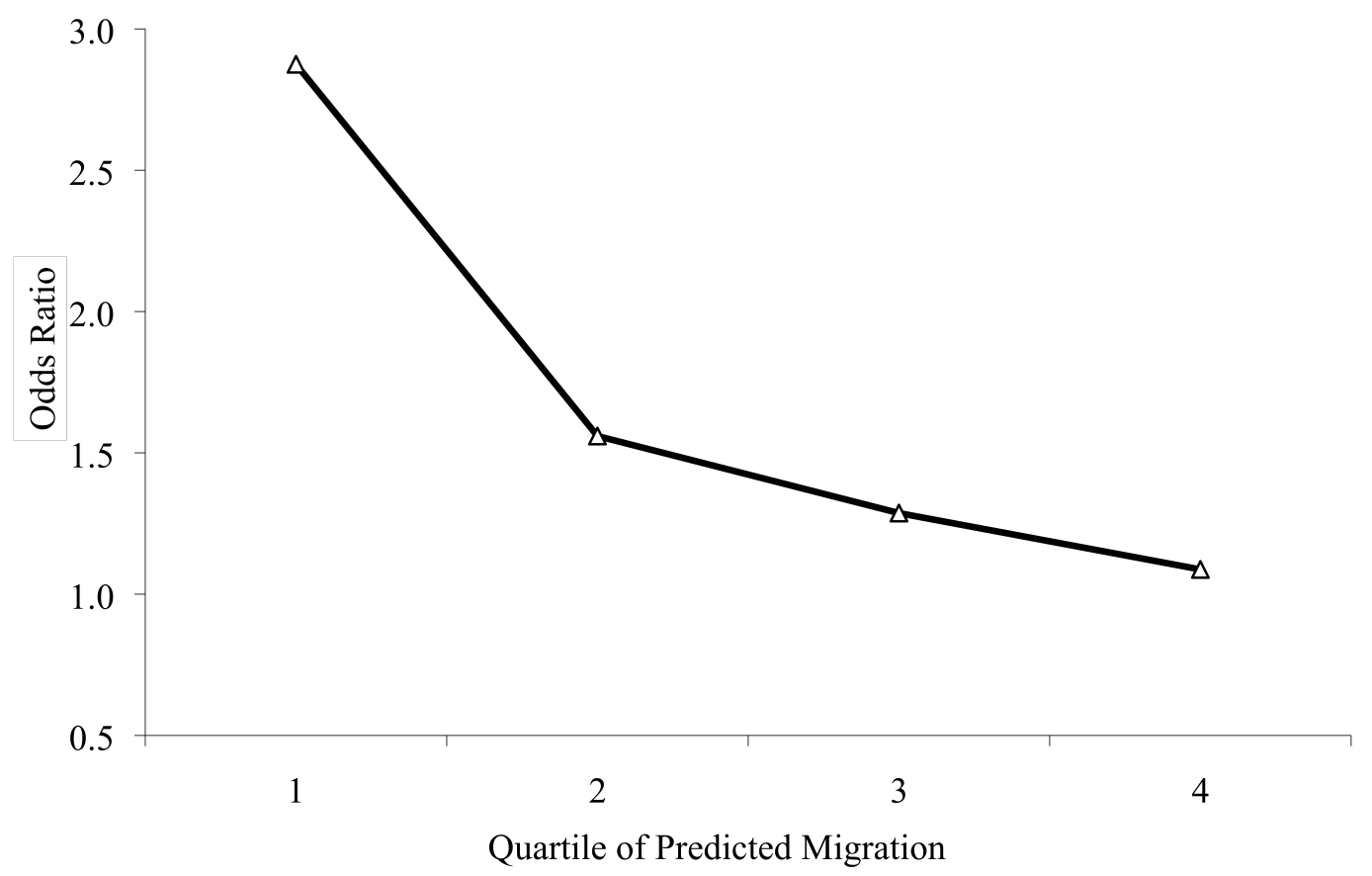

Note: Prediction equation does not contain distance indicators and is fit to subsample of far villages to district ( $>45$ minutes of travel time). 